\title{
Assessment and management of cardiovascular disease in patients with chronic kidney disease
}

\begin{abstract}
Author
Marcelo de Sousa

Tavares $^{1}$

${ }^{1}$ Department of Pediatric Nephrology of the Federal University of Minas

Gerais
\end{abstract}

Submitted on: 08/15/2010

Accepted on: 10/19/2010

Corresponding author: Marcelo de Sousa Tavares Rua Caraça 496, apto 201, Serra

Belo Horizonte - MG -

Brazil

CEP: $30220-260$

E-mail:

tavares.marc@gmail.com

The present study was conducted at the Department of Pediatrics, Medical School, Universidade Federal de Minas Gerais.

Author declare no conflict of interest.

\section{Abstract}

The present letter to the editor compares the difficulties concerning the assessment and management of cardiovascular disease in children and adolescents with chronic kidney disease with those found in adult patients.

Keywords: chronic kidney failure, child health (public health), child mortality, atherosclerosis.

[J Bras Nefrol 2011;33(1): 91-92]@Elsevier Editora Ltda.

\section{DeAr Editor,}

It was with great interest that I read the article Assessment and management of cardiovascular disease in patients with chronic kidney disease by Bucharles SGE, Varela AM, Barberato SH, and PecoitsFilho R. The authors reported the risk factors, methods of assessment, and clinical management of cardiovascular disease (CVD) in adults with chronic kidney disease (CKD). It is worth emphasizing some particularities of the pediatric population affected by CKD.

Cardiovascular disease is known to be the second cause of mortality in children with end-stage CKD. ${ }^{1,2}$ Data from NAPRTCS indicate that the mortality of children starting replacement renal therapy (RRT) is inversely proportional to the age of RRT onset, "cardiopulmonary" being the most common cause of mortality. ${ }^{3}$

Having this in mind, how should the "cardiovascular health" of children with CKD be assessed?

Mortality of cardiovascular etiology in the pediatric population with stage $\mathrm{V}$ CKD is approximately $40 \%$, representing a $700 \%$-increase in mortality as compared with that of the general population (healthy children of the same age bracket).
Endothelial dysfunction occurs early in children with CKD and is followed by calcification of the tunica media, and later left ventricular hypertrophy. Elevations in the levels of systolic blood pressure and intact PTH, calcium and phosphorus, in addition to long periods on dialysis, seem to be important risk factors for CVD in that population. ${ }^{4,5}$ The atherosclerotic process starts in childhood and, even when subclinical, can be assessed by use of the carotid intima-media thickness measurement. That method, however, is not widely available in Brazil and, depending on the patient's age, poses technical difficulties.

Another hindrance is the treatment of dyslipidemia. The lipid levels recommended for children and adolescents are lower than those for adults. Sometimes adequate lipid level control cannot be achieved only with the nutritional approach, requiring the use of lipid-lowering drugs. However, the printed instructions of statins available in Brazil reads "the safety and efficacy of statins for children have not yet been established", which is a frequent cause of questioning by parents, adding one more difficulty to that approach.

One more factor related to the growth deficiency in children with CKD is that, despite the innumerous publications showing the good response to the use of somatotropin, the state secretariats of health have not included the use of that hormone for CKD patients in its list of recommendations.

In addition to the above-cited difficulties faced by pediatric nephrologists, it is worth noting the social difficulties as determinants of greater challenges in the treatment of children with CKD as compared with that of adults. 


\section{References}

1. Mitsnefes MM. Cardiovascular morbidity and mortality in children with chronic kidney disease in North America: lessons from the USRDS and NAPRTCS databases. Perit Dial Int 2005 Feb; 25(Suppl 3):S120-2.

2. McDonald SP, Craig JC for the Australian and New Zealand Paediatric Nephrology Association. Long-term survival of children with End-Stage Renal Disease. N Engl J Med 2004; 350:2654-62.

3. North American Pediatric Renal Trials and Collaborative Studies 2007 Annual Report. Disponível em 08 de agosto de 2010 em https://web.emmes.com/ study/ped/annlrept/annlrept2007.pdf.
4. Lilien MR, Groothoff JW. Cardiovascular disease in children with CKD or ESRD. Nat Rev Nephrol 2009; 5:229-35.

5. Basiratnia M, Fazel M, Lotfi $M$ et al. Sublinical atherosclerosis and related risk factors in renal transplant recipients. Pediatr Nephrol 2010; 25:343-8.

6. Bucharles SGE, Varela AM, Barberato SH. PEcoits Filho R. Avaliação e manejo da doença cardiovascular em pacientes com doença renal crônica. J Bras Nefrol 2010; 32:120-7. 